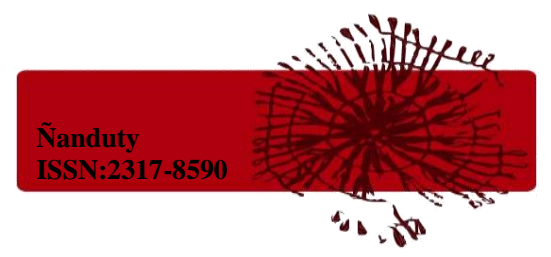

\title{
INIMIGOS AGORA, INIMIGOS OUTRORA: SOBRE ALGUMAS RELAÇÕES PERIGOSAS ENTRE SUJEITOS HUMANOS E SOBRENATURAIS ENTRE OS TICUNA (ALTO SOLIMÕES/AMAZONAS-BRASIL) ${ }^{1}$
}

\author{
Maria Isabel Cardozo da Silva Bueno (Doutora PPGSA/UFRJ; FEPI-Itajubá, \\ mariabelcardozo@gmail.com)
}

\begin{abstract}
RESUMO: Este artigo reflete sobre algumas relações entre sujeitos humanos e não-humanos em uma comunidade ticuna (alto solimões, amazonas, brasil). Serão relacionados alguns mitos sobre inimigos primordiais dos ticuna e os rumores produzidos recentemente sobre os supostos "feiticeiros"/usuários do livro de magia de são cipriano. De acordo com tais rumores, estes últimos passariam por um processo metamórfico que implicaria em sua transformação em $n g o$ 'o, categoria que engloba seres nefastos, muitas vezes referidos como "bichos" na tradução nativa para o português e mesma alcunha atribuída aos inimigos dos tempos primevos.
\end{abstract}

PALAVRAS-CHAVES: Ticuna, Inimizade, Não-Humanos, Amazonia

\begin{abstract}
This article reflects on some relations between human and non-humans subjects in a ticuna community (alto solimões, amazonas, brazil). A few myths about the first enemies of the ticuna will be related to some rumors recently produced on the "wizards"/users of the magic book of saint cyprian. In accordance to the rumors, those supposed wizards would pass through a metamorphical process that would imply in their transformation into $n g o^{\prime} o$, category that engaged dangerous beings, sometimes referred to as "bichos" in the native translation for the portuguese and same denomination attributed to the enemies of the first times.
\end{abstract}

Keywords: Ticuna, Enmity, Non-humans, Amazonia

“Antigamente, o mundo era encantado", explicaram-me, corriqueiramente, diversos Ticuna $^{2}$ com quem convivi ${ }^{3}$. A qualidade de encantado indica que todos os seres do mundo

\footnotetext{
1 Uma versão rudimentar desse artigo foi apresentada numa comunicação oral na XI RAM (Reunión de Antropología del Mercosur, Uruguai, 2015) (Cf. SILVA-BUENO, Maria Isabel Cardozo da, 2015).

${ }^{2}$ Os Ticuna são uma etnia de língua isolada, que ocupa a tríplice fronteira entre Brasil, Peru e Colômbia. Compartilham território com os Yagua, Cocama, Huitoto, Culina e Mayoruna, bem como com a população branca e mestiça dos respectivos países. Somente no Brasil, segundo o Censo Demográfico do IBGE (Instituto Brasileiro de Geografia e Estatística) de 2010, a população ticuna habitante em terras indígenas é de 39.349 pessoas, que vivem em quase 100 aldeias que se espalham por oito municípios da região. Já a população Ticuna que reside fora das terras indígenas é de 9.626, o que resulta numa população total de 46.045 pessoas no Brasil. Os dados do Instituto Socioambiental (ISA) apontam que os Ticuna na Colômbia (dados de 2011) e no Peru (dados de 2007) somam 8.000 e 6.982 pessoas, respectivamente.

${ }^{3}$ Muitas das reflexões aqui apresentadas são fruto da minha tese de doutoramento, que consistiu numa etnografia sobre as relações entre humanos e não-humanos expressas no mito, no rito, nas acusações de feitiçaria e nas mortes por enforcamento numa comunidade indígena ticuna chamada Campo Alegre, pertencente ao município amazonense de São Paulo de Olivença, a partir de trabalho de campo realizado entre os anos de 2010 e 2012
} 
gozavam de um estado de imortalidade, ü'üne. Os humanos tinham acesso a esse estado através do ritual de puberdade feminino. Ao final da festa, a casa ritual flutuava em direção à montanha sagrada chamada Paru, tornando encantados a todos que estavam nela. A perda do acesso ao mundo imortal se deu em virtude do erro de uma worecü, a neófita do ritual de puberdade feminino, que durante sua reclusão atendeu ao chamado do ngo'o da velhice categoria de seres nefastos e perigosos aos humanos, como veremos -, que aproveitou do descuido da moça e trocou de pele com ela, tomando-lhe sua juventude. Como bem mostra o mito, depois de sua primeira menstruação, a moça adentra um estado de vulnerabilidade, sendo extremamente perigoso que ela estabeleça contatos com qualquer ser dito ngo 'o ${ }^{4}$. Por isso, ela é levada à reclusão durante meses, período em que só terá contato com sua mãe e/ou tia paterna. Nesse sentido, por causa do erro de uma moça púbere que os Ticuna conheceram a velhice e a morte.

Os ngo'o são bastante abordados nos mitos dos Magüta, como os Ticuna se autodenominam. Tais relatos trazem histórias dos inimigos primordiais, que impediam a reprodução e crescimento do grupo. Neste artigo, irei apresentar alguns desses mitos, na busca por refletir sobre a relação entre humanos e sobrenaturais no chamado "tempo dos antigos”, para depois estender tal reflexão à forma como se dá esse relacionamento nos dias de hoje, especialmente no que se refere aos perigos da irrupção do sobrenatural na vida cotidiana através das acusações de "feitiçaria" e das decorrentes mortes por enforcamento.

As aspas na palavra feitiçaria, logo acima, são justificadas pelo fato de que, aqui, focarei numa modalidade de enfeitiçamento que tem sido acusada de ser praticada atualmente em algumas aldeias, qual seja aquela pela via do livro de bruxedos de São Cipriano. Segundo contam, aqueles que fazem uso desse livro passariam por um processo metamórfico, sendo muitas vezes referidos também sob a alcunha de ngo’o ou, como dizem em português, esses indivíduos virariam bichos ou vampiros. Estes são, muitas vezes, acusados de serem os responsáveis pelos suicídios ${ }^{5}$, ou melhor, homicídios de jovens na aldeia, o que leva a uma mobilização de seres diversos - caciques e outras lideranças, xamãs,

(Silva-Bueno, 2014). Campo Alegre é uma das comunidades que possuem o maior contingente populacional entre as aldeias Ticuna do lado brasileiro. Os dados da FUNAI (2008) apontam para uma população de 4.389 pessoas e os dados da FUNASA (2010) para 2.196, sendo que o primeiro índice compreende também as comunidades do entorno.

${ }^{4} \mathrm{Na}$ verdade, todos os humanos, independentemente do sexo, estão sujeitos ao contato com os encantados. No entanto, no estado de puberdade, essa vulnerabilidade se torna ainda mais marcada e com consequências ainda mais desastrosas.

${ }^{5}$ Uma reflexão recente sobre o fenômeno do suicídio entre povos ameríndios pode ser encontrada em ARÁUZ; APARICIO (2017) - mais especificamente sobre os Ticuna, ver SILVA-BUENO, 2017. 
pastores e profetas da(s) igreja(s), polícias indígena ${ }^{6}$ e não-indígena... - para identificar os causadores e desmantelar esse mal. Nota-se, pois, o ativamento de uma complexa rede de relações sociopolíticas que esse darkshamanism aciona. Proponho neste artigo, como já mencionado, seguir a via dos mitos, que se mostra profícua para expressar a cosmopolítica das relações entre os Ticuna e seus inimigos, outrora e agora.

\section{OUTRORA: O TEMPO DOS ANTIGOS}

Nos dias de hoje, o acesso aos locais ditos ü'üne não é irrestrito. Quando alguém que os bichos não gostam anda na floresta, eles fazem desaparecer seu destino, fazendo com que a pessoa se perca. Além disso, para entrar e conseguir ver o que há nesses lugares encantados, não se deve ter pensamentos ruins ou possuir um comportamento considerado errado, como por exemplo, ter o costume de beber muito, arranjar brigas e/ou cometer incesto clânico, ou seja, se relacionar com pessoa da mesma metade ${ }^{7}$. Quando uma pessoa se perde na floresta e desaparece, não quer dizer que ela morreu, pois ela pode ter sido capturada por seres encantados (ü'üne), comido a comida que eles lhe ofereceram e, por conseguinte, ter se tornado um deles.

Esses que são, a depender do contexto, traduzidos para o português como encantados ou bichos são classificados na língua nativa através de duas categorias de seres: os ü'üne e os ngo'o. Os ü'üne ou encantados, aqueles seres detentores de um estado de imortalidade,

\footnotetext{
${ }^{6}$ Diversos aldeamentos ticuna do lado brasileiro, especialmente as maiores comunidades, contam com uma organização policial nativa chamada PIASOL (Polícia Indígena do Alto Solimões). Em 2009, esta "polícia nativa" foi bastante exposta na mídia, se encontrando numa situação delicada frente às "polícias da cidade" e da opinião pública em geral. Mais ou menos um ano antes da minha primeira visita à campo, a organização havia sido amplamente exposta na mídia, que divulgava que a Polícia Federal investigava "dois assassinatos e abusos supostamente cometidos por milícias de indios brasileiros na fronteira com a Colômbia e o Peru e o treinamento delas por membros das Farc (Forças Armadas Revolucionárias da Colômbia)" (Brasil, 2008, 2009a, 2009b). Uma dessas mortes teria ocorrido em São Paulo de Olivença: em setembro de 2009, "o corpo de um índio foi achado carbonizado e com as pernas acorrentadas. O motivo seria o envolvimento com feitiçaria". Segundo a notícia, para a PF e FUNAI as ditas "milícias" são ilegais, mas os Ticuna sustentam que as milícias reduziram a criminalidade, argumento que ouvi de vários de meus amigos em campo. Grande parte da minha estadia entre eles foi permeada por uma presença muito forte de acusações de "feitiçarias" - uso, aqui, o plural pois se trata tanto da feitiçaria, digamos, "tradicional" que seria realizada por pajés, quanto daquela que seria praticada através do uso do livro de magia de São Cipriano.

${ }^{7}$ Os Ticuna se organizam em grupos clânicos patrilineares, distribuídos em metades exogâmicas, sendo que cada clã - chamado de nação na tradução nativa - possui como nome um elemento da natureza, podendo ser, de um lado, uma ave, ou de outro, um animal ou vegetal. Melhor dizendo, as nações se dividem entre nações de pena $\mathrm{e}$ nações sem pena. $\mathrm{O}$ membro de uma metade somente poderá se casar com uma pessoa da metade oposta, sendo que os filhos herdam o clã do pai e seus nomes pessoais se relacionam ao clã a que pertencem. A constituição das naçães é explicada no mito de criação, em que os heróis culturais, os irmãos Yoi e Ipi, criaram o gênero humano e atribuíram nações aos Ticuna, ensinando-lhes como deveriam se pintar e casar entre si (Nimuendaju, 1977, 1983; Oliveira Filho, 1988; Goulard, 2009).
} 
compreendem diversos seres ou espíritos do cosmo, dentre eles os próprios ngo 'o. Em outras palavras:

el término ü-üne es un término genérico que abarca tanto a los ngo-ogü ${ }^{8}$, a los 'padres' de los animales como a los 'seres pescados' que acompañaron a los gemelos cuando se produjo la separación original. No tienen forma visible permanente, lo que no significa que no la posean. Esta invisibilidad es relativa (...) (Goulard, 2009: 66).

Numa conclusão óbvia, é possível afirmar que todo ngo'o é um ü'üne, mas o contrário não é verdadeiro. Esquematicamente, os ü'ünegü (encantados; imortais) se opõem aos yunatü (mortais, aqueles que perderam a possibilidade da imortalidade), no entanto, ambos são humanos, sendo que o que os diferencia é o acesso à imortalidade e também a capacidade de mudar de forma. Como afirma Goulard (2009: 66), a noção de ü’üne significa, sobretudo, um estado que os humanos mortais possuem em situações particulares, sendo que o yиüсӥ (o pajé) é o único mortal que pode se aproximar desse estado por ter um "potencial imortal". Quando morre, o pajé vai viver com os "pais" (ou “donos", natü) dos animais.

O termo que engloba todos os seres vivos do mundo (humanos, animais e vegetais) é $d u$ úgü. Sob essa categoria se encontram os Ticuna, que se reconhecem como magüta (povo pintado com jenipapo) ou, ainda, pogüta (povo pescado). Pogüta é o nome dado à primeira "leva" de homens pescados pelos gêmeos primordiais, Yo'i e Ipi, que foi sendo aniquilada por diversos cataclismos (como dilúvios) que ocorreram ao longo do tempo. O motivo dessas catástrofes naturais residia nas relações incestuosas. Só sobreviveram aqueles que se casavam da forma correta, os quais puderam conservar sua forma imortal, ü'üne.

Voltemos, agora, a atenção para a categoria de seres ditos ngo'o. Nimuendaju (1952) e Goulard (2009) afirmam que, segundo os Ticuna, os ngo'o são “demônios". Para Nimuendaju (1952:118), são os seres mais antigos do mundo. Não são imortais ${ }^{9}$, embora muitos tenham poderes que os fazem superior e perigosos aos homens. Alguns desses seres moram na terra, outros no céu, e a maioria nas regiões subterrâneas, que eles acessam através de cavernas. As regiões subaquáticas fazem parte desse submundo, que compreende várias terras de diferentes tipos e entradas. Nesses locais, os ngo'o não são os únicos habitantes, sendo acompanhados por humanos "defeituosos": cegos, anões, pessoas sem ânus. No mundo subaquático, o grande representante dessa categoria de seres é yewae, a

\footnotetext{
${ }^{8}$ A saber, -gü é um sufixo indicador de plural.

${ }^{9}$ Diferente de Nimuendaju (1952), para Goulard (2009: 67) os dados apontam para a imortalidade dos nefastos ngo'o.
} 


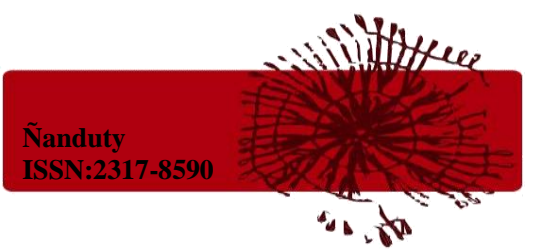

cobra-grande, o 'pai' ou 'dono' dos peixes e/ou dos rios, que causa perigosas correntezas no rio Solimões.

Diversos mitos narram as histórias desses seres, como bem coletou Nimuendaju (1952). Dois mitos em especial, entretanto, nos chamam atenção por parecerem profícuos para nossa reflexão acerca da contemporaneidade entre os Ticuna. Ambos narram o herói Me'tare e sua luta para matar dois demônios Witchicü e Tutchuru, que dizimavam os Magüta nos tempos primordiais. Nos dois casos, Me'tare busca aniquilar o sogro canibal que, usando a beleza da sua filha, atrai os homens que viram suas presas. Comecemos pela luta de Me'tare contra o ngo'o Tutchuru, baseado em como me foi narrada por Seu Abraão, então delegado da PIASOL em Campo Alegre:

Antigamente, no Eware, existia o Me'tare. Antes de o Me'tare existir, já havia gente, mas só que havia também muito bicho (ngo 'o), como essa tal de Onça-preta, chamada Tutchuru, que chupa sangue, como carapanã, mas só que é gente. Tutchuru é inimigo do Ticuna. Tem outro, o Witchicü, que é inimigo também. Tem o Uca'e, outro inimigo. Então, nesse tempo existe o Me'tare, um "santo". Num tempo, uma moça encontrou na roça dela um jabutizinho pequenininho, que era gente. Ela o levou para casa. Passou um tempo, uma semana, e ela sempre estava agradando aquele jabutizinho, sempre dentro do mosquiteiro com ele, conversando com ele. Aí passou um mês e ele vira gente mesmo e conversa com ela: "Será que tu gostas de mim? Se gostar, eu fico contigo". Mas ele nunca tinha se mostrado para ninguém, só aquela menina sabia que ele era gente. Todo tempo ele virava jabuti. Quando ele estava caçando, não era pequeno, virava gente, homem. E estava todo tempo caçando, trazendo alguma caça. Ela era filha do Tutchuru, uma moça bonita, todo homem queria se casar com ela. Sempre que aparecia alguém querendo casar com a filha dele, Tutchuru fazia pamonha, uma panelada para comer com carne de gente. Na hora que seu novo genro ia dormir, quando já estava quase amanhecendo, Tutchuru chupava o sangue dele, ficava só o osso. E, quando amanhecia, o homem estava morto. Aí outro dia, fazia a mesma coisa. Porque a filha dele era bonita, sempre aparecia rapaz querendo ficar com ela. Quando Tutchuru já tinha matado uns cinco homens, aí Me'tare chegou. Ele já sabia que Tutchuru era inimigo. Ele resolveu que ficaria com a filha dele e tentaria vencer o inimigo dele. Ele chegou para o Tutchuru e disse: "Vovô, eu vim aqui contigo, se você gostar e se sua filha gostar, eu quero ficar com tua filha". Tutchuru disse: "Se você quiser, se gostar dela, está aí a minha filha, pode ficar com ela. Eu já me agradei". Aí passaram algumas noites, sem que ele fizesse algo contra Me'tare. Mas quando foi no quinto dia, o Me'tare já sabia do pensamento do Tutchuru. "Agora que ele vai mexer comigo", Me'tare pensou. Então ele fez o seguinte: tirou o pênis dele e colocou na filha do Tutchuru, e a vagina dela, Me'tare colocou no seu próprio corpo. Ele trocou suas partes íntimas com a da esposa para Tutchuru não saber quem era quem na escuridão da noite. Então, à noite, Tutchuru tateou onde estava o pênis e a vagina para saber de quem ia chupar o sangue. Mas como Me'tare inverteu tudo, Tutchuru acabou chupando o sangue da filha dele. Pela manhã, Tutchuru disse, cantando: "Minha filha, levanta". A filha dele 


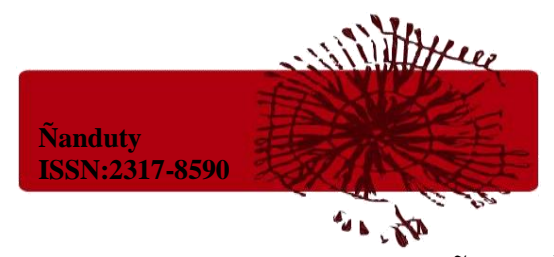

não se levantou mais, já estava morta. Quando seu inimigo terminou de cantar, Me'tare se transformou em japó, que posou numa árvore de abiu no terreiro. Tutchuru ficou chateado por ter comido a própria filha e pensou: "o que eu posso fazer agora? Como que eu vou matar o Me'tare?". Me'tare também queria matá-lo e pousou no telhado de palha da casa dele. Quando Tutchuru olhou para cima, ele furou os olhos do Tutchuru com seu bico grande de Japó. Aí Tutchuru caiu e Me'tare se transformou em homem de novo e matou esse bicho. Se Me'tare não matasse esse bicho, nunca os Ticuna iriam crescer, iriam se acabando com o tempo. Mas ainda há outros bichos.

Na versão colhida por Nimuendaju (1952: 145-6), após comer a própria filha por engano, Tuchuru sobe até o telhado da casa para tentar novamente comer o genro, que lá estava transformado em japó. Ao ter seu olho furado, cai no chão e estoura, o que remete ao tanto que já havia se alimentado antes da carne/sangue da filha. Nesta versão, o ngo'o é referido um percevejo grande, de um meto, justamente por sua capacidade de sucção. Ao narrar o momento em que o pai chupa a carne da filha, tem-se que Me'tare assistiu o corpo da mesma se tornar gradualmente mais flácido e vazio. A versão colhida por Matarezzio (2015: 142) também apresenta essa ideia da retenção de sangue por Tutchuru, que o leva a morte após causar um inchamento, que o faz explodir.

Sigamos com o ngo'o Witchicü, outro sogro aniquilado pelo genro Me'tare:

Noutro tempo, Me'tare foi atrás de outro inimigo, o Witchicü. Este tinha uma filha bonita e todos queriam casar com ela. E acontecia a mesma coisa, passava um dia, dois dias, ele ia fazer pamonha - naquele tempo se fazia muita pamonha. Depois de alguns dias, ele falava para o genro dele: "Olha, meu genro, amanhã nós vamos apanhar patauá". Aí foram lá para o centro da floresta para apanhar patauá, uma árvore bonita que tem um cacho bonito. O genro dele não sabia bem para quê, mas concordou em ir com Witchicü. Levavam também um cesto de pamonha. Já no centro do mato, Witchicü falou para seu genro: "Vai procurando cipó para você subir. Se for por aqui, tem formiga de fogo, nesse lado não tem formiga de fogo". Ele disse isso porque no lado em que disse haver formiga de fogo, estavam os ossos dos homens que ele já tinha comido. Aí o genro foi lá tirar cipó pelo lado que o sogro orientou. Tirou cipó comprido e amarrou no pescoço, pois Witchicü mandou que ele sinalizasse com esse cipó quando estivesse perto dos cachos. O genro trepou na árvore e quando chegou bem perto dos cachos, o sogro puxou e ele caiu no chão e morreu. Aí Witchicü comeu. Antigamente, essa era a história do Ticuna. Esse bicho comeu muita gente. Quando ele já tinha feito isso com outros três genros, Me'tare chegou. Esse Me'tare disse assim: "Vovô, você tem uma filha, eu gosto dela, você deixa eu me casar com ela?". Witchicü respondeu: "Se tu quiseres, eu deixo". Então eles se casaram. Passou dois dias, fez pamonha, e disse assim: "Meu genro, amanhã nós vamos lá apanhar patauá, lá no centro tem um cacho bonito, para nós fazermos vinho". Mas o Me'tare já sabia de tudo. O sogro, mais uma vez orientou: "Não vá por esse lado porque tem muita formiga de fogo e vai te ferrar. Agora, nesse lado não tem formiga de fogo, aí você 


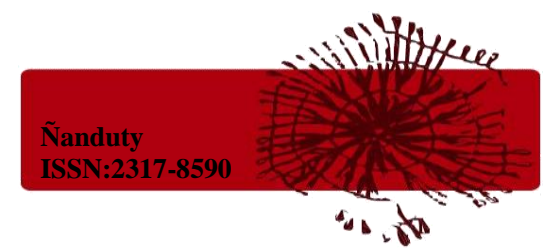

pode ir procurando cipó". Aí Me'tare fica pensando e dá a volta no lugar que o sogro disse para ele não ir e se depara com um monte de osso dos homens que ele já havia comido. Me'tare volta, trazendo o cipó. "Agora, meu genro, você vai subir e colocar o cipó envolto no teu pescoço", disse Witchicü. Me'tare concorda, já sabendo como iria se defender. Ele vai subindo, subindo, até que chega lá em cima, mas ele colocou o cipó na testa. Aí quando ele chega mais lá em cima, seu sogro puxa, mas o cipó escapole. Witchicü não consegue matar ele. Me'tare se transforma em japó e sai voando. Witchicü, cheio de fome, pensa: "Puxa vida, o que eu posso fazer agora? Como que eu posso matar ele? ". Me'tare estava lá em cima, cantando num galho de árvore, e disse: "Se você quer comer, está aí à vontade sua própria carne". Aí Witchicü começa a ter vontade de comer a carne de sua canela. Ele pegou sua faca e começou a comer sua própria carne com pamonha. Come seu peito, seus braços, sua barriga... Até que Me'tare joga em cima do coração dele um carvão que pega fogo e o mata. Aí que os Ticuna puderam crescer mais e mais...

A versão desse mito apresentada por Nimuendaju (1952: 145) traz que Me'tare se transforma em japó e, com seu canto, provoca um estado de encantamento mágico em seu sogro, o que o faz comer-se a si próprio.

As duas narrativas reproduzidas expressam o fato de os ngo'ogü se mostrarem, desde os tempos antigos, como grande ameaça à sobrevivência dos Ticuna. Alguns elementos presentes nesses dois mitos nos auxiliam na tarefa de refletir sobre como essa ameaça é atualizada nos dias atuais. Mas, para tal, é necessário entender de forma mais detida como a alteridade perigosa dos $n g o$ ’o os processos de agressão e morte via enfeitiçamento.

\section{AGORA: BICHOS E VAMPIROS}

A essa altura já está evidente como que, na cosmologia em questão, os ngo'o se apresentam como uma alteridade extremamente perigosa. Esses seres são extremamente nocivos aos humanos, podendo um encontro acidental na roça ou no centro do mato, por exemplo, trazer graves consequências, incluindo a morte. Eles podem, por exemplo, introduzir uma enfermidade em forma de "flechinhas" no corpo da vítima. Alguns encontros desastrosos com os ngo'o ocorrem num momento de embriaguez da pessoa, fato também observado por Goulard (2009: 286). Quando a pessoa está embriagada, seu "princípio vital"10 está enfraquecido, momento favorável para que um ngo'o se aproxime e se aproveite

\footnotetext{
${ }^{10}$ Goulard (2009: 67-69) explica as modalidades da constituição do $d u$ - $\tilde{u}$ (ser vivo). Um "princípio energético", o pora, permite seu crescimento e assegura sua permanência, referindo-se a uma noção de força, uma energia. $\mathrm{O}$ ser se constrói a partir do crescimento de seu pora até alcançar um estado, possuir uma "quantidade" suficiente que permite a reprodução do ciclo vital, assegurando a manutenção do "princípio vital" ( $a-e$ ). Esse processo se desenvolve em cada indivíduo, a partir dos critérios englobados na noção de $m a-\tilde{u}$, ou seja, o "princípio
} 
$s \Delta$,

para introduzir uma doença em seu corpo. São seres invisíveis, que podem se tornar visíveis e assumir qualquer forma, inclusive humana, especialmente para enganar os humanos, levando-os até mesmo a se enforcarem. Os ngo'o podem atacar as pessoas que cometem incesto clânico por se relacionarem com o mesmo sangue.

A esses mesmos seres maléficos os pajés-feiticeiros recorrem para acarretar males às suas vítimas. Uso essa expressão pajé-feiticeiro para destacar a intenção do pajé (yuücü) de acordo com um contexto específico, pois, entre os Ticuna, o xamã pode fazer o mal e o bem, não havendo uma figura destacada e/ou virtual de "feiticeiro", como em outras etnias. O yиüсӥ (pajé, como é traduzido no lado brasileiro) se relaciona com os espíritos das árvores e/ou com os ngo'ogü de uma forma dúbia, podendo tal relação ser de predação ou não, ou seja, se pautar tanto na intenção de provocar a morte, quanto na promover a cura.

Uma vendeta contemporânea provinda de uma acusação de feitiçaria envolve o acusado, a vítima, as famílias, o pajé que identifica o agressor e a parcela de não-humanos acionados tanto para o suposto feitiço (ngo'gü ou ngogü, feitiço que causa morte), quanto para descobrir o autor do mesmo e, possivelmente, para revidá-lo como forma de vingança. Além desses termos indispensáveis, nota-se também a presença do cacique - ou dos caciques, visto que o conflito pode se instalar entre aldeias -, o pastor e o(s) profeta(s) da Igreja Batista ${ }^{11}$ e a polícia indígena, sob a gerência do delegado eleito em assembleia. Aliás, tendo em vista a forte presença da Igreja, é possível incluir também, naquela parcela de seres não-humanos, o Espírito Santo e o Diabo, em especial quando o mal causado tem como veículo as receitas do Livro de São Cipriano.

Antes de abordar a curiosa presença do Livro entre os Ticuna, é válido mencionar brevemente o que representa o Livro de São Cipriano, enquanto edição de sucesso entre as massas nas cidades brasileiras de grande e pequeno porte. A bem da verdade, segundo Ferreira (1992: XVI-XVII), ainda que sob uma aura de sigilo e mistério, o livro é de conhecimento amplo e frequente na sociedade rural brasileira, que deste modo segue seu “caminho da cidade". A expansão em território brasileiro está ligada à umbanda, religião afro-brasileira, sendo que além de alcançar um público esparso por várias cidades, ele visa também um grupo de migrantes, que vivem nas grandes cidades brasileiras, em busca de

corporal”, sua identidade. Segundo o autor, o corpo é a parte material visível, mas o apreciam como o resultado da atividade de outros componentes que estão em interação e sem os quais não se poderia existir. Se poderia sintetizar a concepção ticuna do Ser como o "corpo dos afetos".

11 Campo Alegre foi fundada em 1959 por pastores norte-americanos da Association of Baptists for World Evangelism, que chegaram ao Alto Solimões com a intenção de converter a população local, visando inicialmente a população ribeirinha (Macedo, 1996,1999). Nos dias de hoje, a presença da religião permanece com força, contando com uma grande igreja, casas de oração, pastores e profetas nativos. É grande também o trânsito destes pastores e profetas e fiéis entre as comunidades ticuna próximas e mais distantes. 
adaptação aos espaços urbanos ${ }^{12}$. O livro é um livro de magia, que traz consigo uma carga de maldição e tem sua produção, circulação e consumo regulados por certos princípios e tabus ${ }^{13}$.

O livro com as receitas de Cipriano teria sido introduzido em Campo Alegre por pessoas que viajam até Letícia (cidade colombiana que faz fronteira com Tabatinga, no lado brasileiro), conhecem o livro e são atraídos pelas promessas nele contidas, trazendo exemplares para vender na aldeia. Outra forma de entrada seria através dos mascates peruanos, que entram na comunidade vendendo utensílios diversos (roupas, panelas, etc). O uso desse Livro não se restringe, de forma alguma, à Campo Alegre, mas também se ouve notícias de seu uso em outras comunidades do lado brasileiro e peruano.

A presença desse Livro é uma presença, na verdade, ausente, pois é um livro oculto, do qual todos falam, mas nunca alguém afirma já tê-lo visto. É objeto de grande curiosidade, inclusive daqueles que mais criticam seu uso. Muitos acreditam que o livro é responsável pelos enforcamentos. Seus leitores-seguidores, atraídos pela ilusão de conseguirem dinheiro e bens (moto, loja, etc.), fazem "pacto com o diabo" através do livro de São Cipriano. Aí, quando não conseguem o que almejavam, atentam contra a própria vida. Outros usos dizem respeito a magias de amor, que podem conduzir a vítima à loucura, levando-a a cometer suicídio.

Nessas condições, de um modo geral, temos que o mal veiculado pelo livro de São Cipriano pode levar à doença, à loucura e ao suicídio da vítima e à transformação de seu usuário em ngo'o, categoria que, nesse contexto, pode passar pela tradução nativa de "bicho" ou "vampiro". Em se tratando da técnica de enfeitiçamento, os que provocam o mal através do livro de São Cipriano, o fazem através da leitura do livro e da escrita do nome da vítima nas páginas do livro. Eles também podem fazê-lo através de uma "coleção" de peças de roupas, fotografias e outros itens das suas vítimas.

Vale notar também uma similaridade com a potência curativa e patogênica centrada na figura do pajé: o livro também pode ser usado para o bem, a depender de quem o maneja. Um senhor me explicou: pode-se usar para coisa boa, para ficar rico, construir uma casa

\footnotetext{
${ }^{12}$ Ouvi de um vendedor de uma grande rede de livrarias em Belo Horizonte que, atualmente, esse livro tem grande saída para um público adolescente fãs de filmes que abordem bruxaria, como o caso do personagem Harry Potter.

${ }^{13}$ Nota-se a presença desse (ex-)bruxo no Brasil na literatura de folhetos nordestinos, os cordéis: "Seus leitores são aqueles de rodoviária, como informa um dos seus 'autores'. É das classes populares das mais diversas proveniências que vem a necessidade desses textos, em sucessivos e diferentes produtos editoriais, em Portugal, no Brasil e em outros países da América Latina, mas pode-se dizer que ele vai avançando, atinge pessoas de classe média, de maior poder aquisitivo e, em geral, filiadas a crenças espíritas pertencentes ao que se definiu como um "contínuo mediúnico" (FERREIRA, 1992: XVII).
} 
bonita, mas só pode ler aquela página que possibilita isso, pois se ler o resto, ou a pessoa enlouquece, ou vira ngo'o. Alguns dizem que feitiçaria de pajé é mais forte que a agressão via livro. Outros (menos frequentes) afirmam o contrário. Fato é que, diferente do vasto conhecimento de toda a terapêutica xamânica envolvida na cura e/ou vingança de um feitiço supostamente lançado por alguém, no caso do Livro, a terapêutica para reverter o mal causado por uma "receita de Cipriano" é ainda pouco conhecida, justamente por ser uma técnica "exógena". Aliás, meus interlocutores foram taxativos ao afirmarem que aquilo que é feito através do Livro de São Cipriano não é feitiçaria, nos termos da técnica específica praticada pelo yuӥсü.

A potência e intencionalidade agressiva do "bicho-vampiro", praticante das receitas de Cipriano, é contada em diversos casos que teriam ocorrido em Campo Alegre e noutras aldeias. Muitos desses casos descrevem pessoas que, através do Livro, adquiririam a capacidade de voar para vários lugares do mundo e de se transformar em animais e passear por debaixo da terra. Um dos casos conta que o "vampiro" viajou "acoplado" num avião para outro país com outros ngo'ogü, que apareciam sob a forma de americanos ${ }^{14}$, e, numa visita a um hospital, sugou o sangue de doentes lá internados. Outros casos descrevem pessoas que iam por debaixo da terra até o cemitério se alimentar da carne fresca dos mortos. A força de tais rumores era tanta que os parentes das pessoas que morriam naquele período ou estavam se recusando a enterrá-los em Campo Alegre, ou faziam vigília nas primeiras noites em que o corpo havia sido enterrado para que o mesmo não fosse violado e comido pelos "bichos".

Geralmente, essas histórias se originam de depoimentos que ex-“usuários" do Livro ou seus familiares dão aos membros Igreja. Grande parte dos depoentes se encontravam em condição de enfermidade por terem ingerido grande quantidade de carne fresca dos mortos; e pediam perdão a Deus pelos seus pecados, confessando-se arrependidos. Vale enfatizar, nessas condições, que esses "pecadores" já se encontravam num processo metamórfico avançado: já seriam ngo’o.

\footnotetext{
${ }^{14}$ Essa representação do branco estrangeiro (e, aqui, pode-se incluir o branco de São Paulo "do Sul") enquanto usurpador por excelência dos conhecimentos indígenas é bastante marcado nas comunidades que visitei. São várias as histórias de barcos de estrangeiros que aportam para conhecer as plantas medicinais e até para estudar a constituição física das pessoas (através de coletas de sangue, por exemplo), que evocam, claramente, as conhecidas situações de biopirataria na Amazônia. Ver também as análises dos Gringos corta-cabeças por Goulard (1992).
} 
$\Delta \Delta, \ldots$

interdito de contato entre o matador e os despojos do inimigo; a abstinência sexual do matador, associada a restrições alimentares e de conduta; anexação de atributos metonímicos da vítima, como alma, nomes e cantos.

Viveiros de Castro (2002: 287) recorda a concepção de sangue enquanto indutor ou signo de uma mudança de estatuto metafísico e, nesse caso, segundo ele, a morte da vítima é a morte do matador, na mesma medida em que o renascimento deste é o renascimento daquela. No caso da ingestão literal do sangue e da carne pelos bichos-vampiros nenhum indício leva a um "comércio espiritual" que se reproduza em relação, pois esse sangue causa inchamento, expansão interna, morte. No caso dos vampiros, a ingestão do sangue induz a metamorfose dos indivíduos em bicho. Só que essa mudança metafísica não se finda em relação com o Outro interiorizado - não é, portanto, predação ou preensão -, é apenas aniquilação. Pelo que pude presenciar em campo, parece não ser possível uma terapêutica, ou melhor, um rito de reversão dessa "fusão" do bicho e sua vítima via ingestão literal de seu sangue/carne. Mas, caso haja essa possibilidade, a questão que emerge é se essa terapêutica será xamânica ou via profetas da Igreja Batista.

Vimos que o encontro com os ngo'o é perigoso, principalmente se a vítima estiver numa condição liminar, como é o caso da worecü. No entanto, podemos pensar que os rapazer púberes também se encontram num contexto de vulnerabilidade, que pode ser expressa nas histórias de Me'tare quando estas ilustram bem a relação potencialmente conflituosa entre genro e sogro durante o período de bride-service, de acordo com a regra de uxorilocalidade $^{15}$. Nesse período, o genro deve ajudar seu sogro até que possa ter uma boa roça e sua própria casa para morar com sua família, sendo que esse período pode se estender por um tempo considerável. Goulard (2009: 237) descreve essa situação para o caso dos Ticuna que vivem em malocas ${ }^{16}$ no que diz respeito à competição do genro com seu sogro e cunhados; esta situação não é muito diferente daquela que encontrei durante o trabalho de campo. Interessante notar que Me'tare se encontra sob o mesmo estado de boa parte dos jovens que são encontrados mortos enforcados, visto que o suicídio entre os Ticuna é

\footnotetext{
${ }^{15}$ Essa relação entre sogro e genro e o mito de Me'tare foi notada no trabalho de Erthal (1998) acerca do suicídio entre os Ticuna.

${ }^{16}$ Como notou Nimuendaju (1952: 11), a habitação original dos Ticuna era uma grande, isolada e comunal maloca, ocupada por mais de uma família. Os Ticuna passaram por um processo de intenso contato, principalmente a partir do final do século XIX, com o ciclo da empresa seringalista. No decorrer do tempo, foram diversas as transformações que se sucederam, dentre elas o quase total desaparecimento das malocas clânicas - ainda é possível encontrá-las do lado colombiano, como registrou Goulard (2009) - e o surgimento dos aldeamentos; as missões protestantes; e os movimentos messiânicos.
} 
predominantemente masculino e ocorre na fase em que os jovens, geralmente, se casam ${ }^{17}$. Aliás, ainda que não possa embasar estatisticamente a afirmação que segue, os relatos que colhi indicaram que o perfil dos acusados de utilizarem o livro, são massivamente homens jovens.

Os mitos percorridos ilustram as tentativas de dizimar os Magüta realizadas por seres

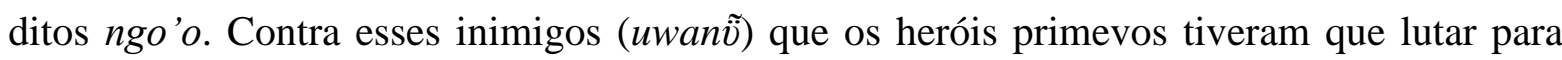
que os Magüta pudessem subsistir até hoje, num mundo em constante transformação. No entanto, é notável que a "guerra cosmológica" contra esses seres ainda continua nos tempos atuais. Nos termos expressos por Whitehead e Wright (2004: 1-3), na tentativa de dar conta de um dark shamanism, os corpos se tornam o lugar das disputas cosmológicas, tanto os corpos físicos quanto políticos, que são criados e destruídos através das ações rituais e políticas dos chefes, guerreiros, xamãs e profetas.

Nesse sentido, o mito atualizado e transformado na história vivida dos Ticuna se configurou como uma importante ferramenta para se compreender como são acionados os vários registros de interpretação, que envolvem as acusações de feitiçaria e o uso do Livro de São Cipriano. Através das histórias dos antigos podemos refletir sobre a agência dos seres invisíveis, especialmente os ngo'o, sua agência invisível e sua presença no cotidiano entre os Ticuna.

\footnotetext{
${ }^{17}$ O Relatório de Gestão da FUNASA a respeito da etnia Ticuna, referente ao ano de 2009, aponta a ocorrência de 21 óbitos por suicídio, sendo 18 masculinos e 3 femininos. O suicídio (e as tentativas de suicídio) seria, segundo esses dados, predominantemente masculino. Erthal (2001: 310) nota que 74,6\% dos suicídios no período foram de homens, enquanto que $25,4 \%$ foram de mulheres. No caso das mortes de pessoas do sexo masculino, os casos de suicídio se concentraram nas faixas etárias de 16-18 anos (43,6\% dos casos) e 19-25 anos (18,2\% dos casos). No caso das mulheres, a maior parte das mortes ocorreram na faixa etária de 19-25 anos $(9,1 \%)$. A forca foi tida como o principal meio utilizado para a morte, ainda que constassem alguns casos de ingestão de timbó (ou outras substâncias, como hipoclorito de sódio) e o uso de arma de fogo. Ainda que não tenhamos essa mesma projeção atualizada e referente também às outras regiões do Alto Solimões em que residem os Ticuna, os números trazidos por Erthal $(1998,2001)$ são interessantes dispositivos para reflexão sobre o papel de gênero no ciclo de vida dos jovens Ticuna.
} 


\section{REFERÊNCIAS BIBLIOGRÁFICAS}

ARÁUZ, Lorena Campo; APARICIO, Miguel. (2017) (Org.). Etnografías del suicidio en América del Sur. 1ed.Quito: Editorial Universitaria Abya-Yala.

BRASIL, Kátia. (2008) Índios gays são alvo de preconceito no AM. Folha Online. Disponível em: <http://www1.folha.uol.com.br/fsp/brasil/fc2707200821.htm>. 27 jul. 2008. Acesso em: 10 ago. 2010.

(2009a) PF investiga elo das Farc com milícias de indígenas no AM. Folha Online. Disponível em:<http://www1.folha.uol.com.br/folha/brasil/ult96u652675.shtml $>$. 15 nov. 2009a. Acesso em: 10 ago. 2010.

(2009b) Milícia indígena quer armas e patentes. Folha Online. Disponível em: <http://pib.socioambiental.org/es/noticias?id=75081\&id_pov=259>. 17 nov. $2009 \mathrm{~b}$. Acesso em: 10 ago. 2010.

ERTHAL, Regina Maria de Carvalho. (1998). “O suicídio Ticuna na região do Alto Solimões - AM". Tesis Doctoral, Escola Nacional de Saúde Pública, Fundação Oswaldo Cruz, Rio de Janeiro.

. (2001). "O suicídio Tikúna no Alto Solimões: uma expressão de conflitos”. Caderno de Saúde Pública, 17, p. 299.

FERREIRA, Jerusa Pires. (1992). O livro de São Cipriano: uma legenda de massas. Perspectiva: São Paulo.

FUNAI: CGETNO/FUNAI (Coordenação Geral de Etnodesenvolvimento Sustentável da Fundação Nacional do Índio).

FUNASA (Fundação Nacional de Saúde). Disponível em: http://sis.funasa.gov.br/transparencia_publica/siasiweb/Layout/quantitativo_de_pessoas_201 0.asp. Acesso em: 10 ago. 2010.

GOULARD, Jean-Pierre. (1992). "Les Tikuna n'ont pas de loi ou le motif de la 'Tête Coupée"”. Journal de la Société des Américanistes, 78, p. 8.

. (2002). "Les temps du passage: exister pour vivre. L'entre-deux chez lês Ticuna d'Amazonie". L'autre: Cliniques, cultures et sociétés, 3, p. 109.

la Amazonía”. Lima: Caaap-Ifea.

(2009). "Entre mortales e Immortales: el ser según los Ticuna de

MACEDO, Guilherme Martins de. (1996). "Negociando a identidade com os brancos: religião e política em um núcleo urbano Tikúna". Tesis de Maestría, Museu Nacional, Universidade Federal do Rio de Janeiro, Rio de Janeiro. 


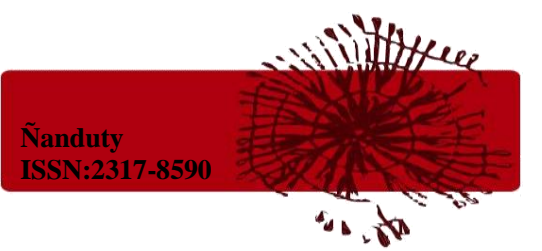

(1999). “A conversão cristã e a identidade Ticuna: a trajetória de Campo Alegre”. Amazônia em Cadernos, 5, p. 175.

MATAREZIO FILHO, Edson Tosta. (2015). A Festa da Moça Nova: ritual de iniciação feminina dos índios Ticuna. Tese (Doutorado em Antropologia Social) - Faculdade de Filosofia, Letras e Ciências Humanas, Universidade de São Paulo, São Paulo.

NIMUENDAJU, Curt. (1952). "The Tukuna". Berkeley and Los Angeles: University of California Press.

Instituto Brasileiro de Geografia e Estatítica: Censo 2010. Disponible en: $<$ http://www.censo2010.ibge.gov.br/>.

Instituto socioambiental. Disponible

en:

<http://www.socioambiental.org/pib/epi/ticuna/ticuna.shtm>.

LIVEIRA FILHO, J. P (1988). O nosso governo: os Ticuna e o regime tutelar. São Paulo: Marco Zero; Brasília: MCT/CNPq.

SILVA, Maria Isabel Cardozo da. (2012). "Algumas reflexões sobre feitiçaria entre os Ticuna (Alto Solimões-AM)”, 36 ENCONTRO ANUAL DA ANPOCS, 2012.

SILVA-BUENO, Maria Isabel Cardozo da. (2014). Sobre encantamento e terror: imagens das relações entre humanos e sobrenaturais numa comunidade Ticuna (Alto Solimões, Amazonas, Brasil). Tesis Doctoral, Instituto de Filosofia e Ciências Sociais, Universidade Federal do Rio de Janeiro, Rio de Janeiro.

(2015). Inimigos de outrora, inimigos de agora: algumas relações possíveis entre mitos e o Livro de São Cipriano entre os Ticuna (Alto Solimões - Amazonas - Brasil). XI REUNIÓN DE ANTROPOLOGÍA DEL MERCOSUR.

(2017). Suicídio ou homicídio? Os múltiplos sentidos das mortes por enforcamento entre os Ticuna (Alto Solimões, Brasil). In: Lorena Campo Aráuz; Miguel Aparicio. (Org.). Etnografías del suicidio en América del Sur. 1ed.Quito: Editorial Universitaria Abya-Yala, v. p. 123-147.

TICUNA. Instituto Socioambiental. Disponível em: 〈http://www.socioambiental.org/pib/epi/ticuna/ticuna.shtm>. 
VIVEIROS DE CASTRO, Eduardo (2002). Imanência do inimigo. In: A inconstância da alma selvagem: e outros ensaios de antropologia. São Paulo: Cosac\&Naify, p. 267-294.

WHITEHEAD, N. L.; WRIGHT, R (Org.). (2004). In Darkness and Secrecy: The anthropology of assault sorcery and witchcraft in Amazonia. Durham, NC: Duke University Press. 